\title{
Crystallographic Texture Development and Its Effect on Corrosion Behavior of Pilgered Zirconium Alloy Tubes
}

\author{
Yong Choi $^{1}$ and Hirofumi Inoue ${ }^{2}$ \\ ${ }^{1}$ Department of Advanced Materials Engineering, Sunmoon University, \\ 100 Kalsan-Ri, Tangjeoung-Myun, Asan, Chungnam 336-840, Korea \\ ${ }^{2}$ Department of Materials Science, Osaka Prefecture University, Sakai 599-8531, Japan
}

\begin{abstract}
Crystallographic texture and corrosion of zirconium alloy tube with pilgering were studied. Average grain size of the cross-sectional surface of the tube was changed from $28 \mu \mathrm{m}$ to $11 \mu \mathrm{m}$ by $1 \mathrm{st}$ pilgering, and to $8 \mu \mathrm{m}$ by 2 nd pilgering. Aspect ratios of the elongated grains on longitudinal surface of as-received, 1st and 2nd pilgered tubes are 1,6 and 12, respectively. Micro-hardnesses of the tubes are 172, 218 and $246 \mathrm{Hv}$ for their cross sectional surfaces and 180, 233 and $252 \mathrm{Hv}$ for their longitudinal surfaces, respectively. Pilgering results in increasing the (0001) basal and $\{10 \overline{1} 0\}$ prismatic pole densities to TD (tangential direction) split type and $\mathrm{AD}$ (axial direction) concentration type, respectively. A preferred orientation is mainly formed by 1st pilgering. Further pilgering produces a texture of $(\overline{1} 2 \overline{1} 4)[10 \overline{1} 0]$ with a significant spread around [1010] parallel to $\mathrm{AD}$. Corrosion potential and corrosion rate of the zirconium alloy tubes in dearated aqueous $5 \% \mathrm{NaCl}$ solution $(\mathrm{pH}=6.3)$ at $20^{\circ} \mathrm{C}$ are in the range of $-0.552 \sim-0.767 \mathrm{~V}_{\mathrm{SHE}}$ and $1.88 \times 10^{-7} \sim 12.02 \times 10^{-7} \mathrm{~A} / \mathrm{cm}^{2}$, respectively. Crystallographic anisotropy influences corrosion behavior of the zirconium alloy tubes. Pilgering results in reducing corrosion potential and increasing corrosion rate due to grain size refinement and increased dislocation density rather than crystallographic texture. [doi:10.2320/matertrans.MG200911]
\end{abstract}

(Received October 15, 2009; Accepted December 17, 2009; Published February 17, 2010)

Keywords: crystallographic texture, zirconium alloy, hexagonal close-packed (HCP), orientation distribution function, anisotropic corrosion

\section{Introduction}

Seamless zirconium alloy tubing has been widely used for many years in chemical and nuclear engineering fields. ${ }^{1)}$ The seamless tubing is generally produced by pilgering which results in forming unique crystallographic texture of the zirconium alloy tube with hexagonal close-packed (HCP) structure. Since the crystallographic texture plays an important role in mechanical and chemical properties such as strength, creep and hydride formation, the study of the crystallographic texture is one of the important issues from the engineering point of view in their fields. $\left.{ }^{2,3}\right)$

The crystallographic texture can be determined by various techniques such as neutron, electron and X-ray beams by using Bragg's law and Kikuchi patterns. Neutron diffraction technique is useful to measure the diffraction of entire volume of the specimen rather than its surface because neutron can easily penetrate through the materials with the size of millimeters due to relatively weak interaction with matter. However, it requires large volume of the samples so that it is unsuitable for thin films or thin sheets. ${ }^{4)}$ Electron backscattered diffraction (EBSD) is useful to analyze a local area like a grain because it uses a narrow beam of low energy electrons by a scanning electron microscope, however, it strongly depends on the surface condition of the sample and requires additional surface treatment of the sample to remove surface roughness and strain. ${ }^{5)} \mathrm{X}$-ray diffraction technique has advantages of measuring the texture of near surface of the sample in air, however, it is limited to an angular range because of the usage of a goniometer. ${ }^{6}$ )

Although there are lots of studies on the analysis of crystallographic texture and its effect on mechanical properties, little information is available about the effect of crystallographic texture on corrosion behavior of the alloys. ${ }^{7)}$ Hence, in this study, crystallographic texture of the pilgered zirconium alloy tubes was analyzed and their corrosion behaviors on different surfaces were determined to study the effect of crystallographic texture on the corrosion behavior and give basic data for the fabrication of zirconium alloy tube.

\section{Experimental Method}

\subsection{Sample preparation}

Zirconium alloy tubes with the same lot but different pilgering processes were used to give different texture conditions. The sample was prepared by using conventional metallurgical processing to control microstructure and crystallographic texture. Outer diameter (O.D), inner diameter (I.D) and wall thickness (W.T) of as-received tube before pilgering were $63.5,41.6$ and $10.9 \mathrm{~mm}$, respectively. Q-ratio and elongation factor for pilgering were 1.13 and 4.2 for $1 \mathrm{st}$ pilgering, and 1.99 and 4.6 for 2 nd pilgering, which matched $76.4 \%$ and $78.5 \%$ reductions of area, respectively. Here, Q-ratio is defined as a ratio of the logarithmic strain in tube wall thickness before and after pilgering to the logarithmic strain in tangential direction at mid wall thickness before and after pilgering. ${ }^{8)}$ Figure 1 is a flow sheet of the fabrication of the zirconium alloy tube. Table 1 is chemical composition of the zirconium alloy tube used in this study.

\subsection{Characterization}

Each tube was sectioned parallel to the longitudinal direction of the tube to prepare specimens for microstructure observation and texture analysis. Microstructure was observed by polarized optical microscopy (Nikon Optiphot 200, Japan) and scanning electron microscopy (Jeol JSM-6400, Japan), respectively. Specimen for optical microscopy was cold-mounted with conductive reagent and polished up to $0.3 \mu \mathrm{m}$ diamond paste followed by etching with the solution of $\left(\mathrm{HF}: \mathrm{HNO}_{3}: \mathrm{HCl}: \mathrm{H}_{2} \mathrm{SO}_{4}: \mathrm{H}_{2} \mathrm{O}=1: 3: 1: 2: 3\right)$. Texture was determined by $\mathrm{X}$-ray diffractometry (Shimazu 


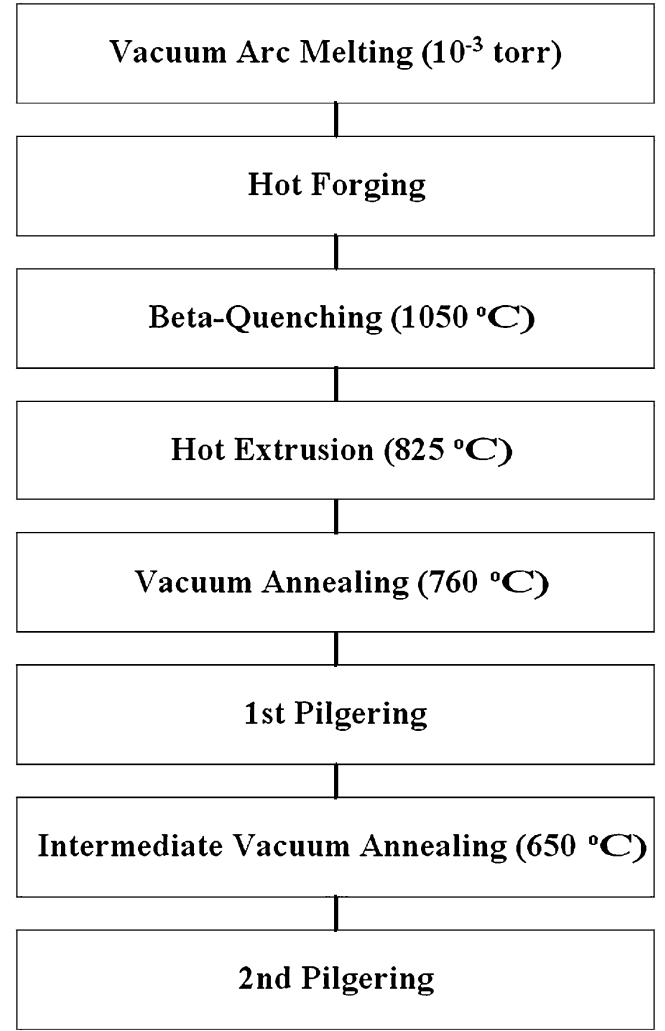

Fig. 1 Flow sheet of specimen preparation.

Table 1 Chemical composition of zirconium alloy tube used in this study (mass\%).

\begin{tabular}{llllllllll}
\hline Element & $\mathrm{Nb}$ & $\mathrm{Sn}$ & $\mathrm{Fe}$ & $\mathrm{Cr}$ & $\mathrm{Ni}$ & $\mathrm{H}_{\mathrm{f}}$ & $\mathrm{C}$ & $\mathrm{O}$ & $\mathrm{Zr}$
\end{tabular}

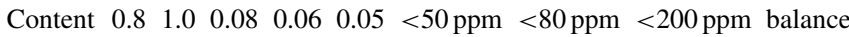

XD-3A, Japan). Specimen for texture analysis was prepared by stacking the longitudinally sectioned pieces. The pieces of the tube with $20 \mathrm{~mm}$ in length were cold-mounted and polished up to $0.3 \mu \mathrm{m}$ diamond paste followed by electrochemically polishing with the solution of $\left(\mathrm{HF}: \mathrm{HNO}_{3}\right.$ : $\left.\mathrm{H}_{2} \mathrm{O}=10: 45: 45\right)$. Four incomplete pole figures of $\{10 \overline{1} 0\}$, (0001), $\{10 \overline{1} 1\}$ and $\{10 \overline{1} 2\}$ were measured in the $\alpha$-angle range of 0 to 75 degrees by the Schulz reflection method using $\mathrm{CuK} \alpha$ radiation. Background correction was conducted using the intensity at two positions of the $\{10 \overline{1} 0\}$ diffraction angle $2 \theta_{1}$ minus 2 degrees and the $\{10 \overline{1} 1\}$ diffraction angle $2 \theta_{2}$ plus 2 degrees for three diffraction planes of $\{10 \overline{1} 0\}$, (0002) and $\{10 \overline{1} 1\}$ with adjacent angles, and the intensity at two positions of the diffraction angle $2 \theta \pm 2$ degrees for a $\{10 \overline{1} 2\}$ diffraction plane. Defocus correction was performed using the intensity of a randomly oriented powder zirconium sample. From these incomplete pole figures, the orientation distribution function ${ }^{9)}$ was calculated up to the 16th order by the iterative series expansion method with ghost correction ${ }^{10)}$ using a computer program produced by one of the authors. Micro-hardness was determined by Vickers micro-hardness tester (Buehler micro-Vickers 5100, USA). Corrosion test was carried out by potentiodynamic method (Gammy CMS 300, USA) in deaerated aqueous $5 \% \mathrm{NaCl}$ solution $(\mathrm{pH}=6.3)$ at $20^{\circ} \mathrm{C}$.

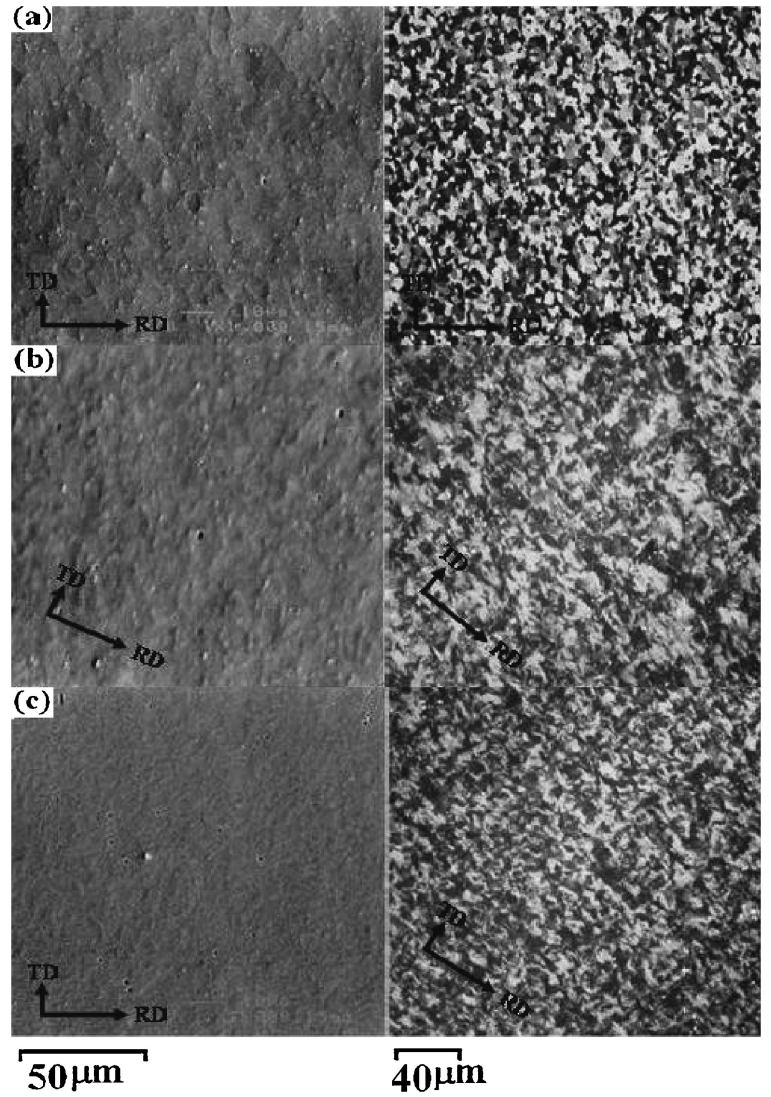

Fig. 2 Microstructure of cross-sectional surface of zirconium alloy tubes observed by SEM (left) and polarized optical microscopy (right): (a) asreceived, (b) 1st pilgered and (c) 2nd pilgered tubes. RD and TD are radial and tangential directions of tube, respectively.

\section{Results and Discussion}

\subsection{Microstructure and hardness}

Figures 2 and 3 are the microstructure on cross-sectional and longitudinal surfaces of the pilgered zirconium alloys observed by scanning electron microscopy and polarized optical microscopy, respectively. As shown in Figs. 2 and 3, the as-received tube has equiaxed grains. The pilgered tubes have refined grains on the cross-sectional surface of the tube and elongated grains on the longitudinal surface of the tube, respectively. Average grain size of the cross-sectional surface of the zirconium alloy tube is $28 \mu \mathrm{m}$ for as-received, $11 \mu \mathrm{m}$ for $1 \mathrm{st}$ pilgered, and $8 \mu \mathrm{m}$ for 2 nd pilgered tubes, respectively. Aspect ratios of the elongated grains on the longitudinal surface are 6 for 1st pilgered, and 12 for 2 nd pilgered tubes, respectively.

Table 2 is micro-hardness changes of zirconium alloy tube surfaces with pilgering. As shown in Table 2, the microhardnesses of the cross-sectional and longitudinal surfaces of the as-received zirconium alloys are 172 and $180 \mathrm{Hv}$, respectively. Those values are increased to 218 and $233 \mathrm{Hv}$ by 1 st pilgering, 246 and $252 \mathrm{Hv}$ by 2nd pilgering, respectively. Considering the rate of hardness change, the hardness is mainly increased by 1 st pilgering. The anisotropy of the hardness on the cross-sectional and longitudinal surfaces is due to the texture formation of the zirconium alloy tube by pilgering. The improved hardness is related to grain 


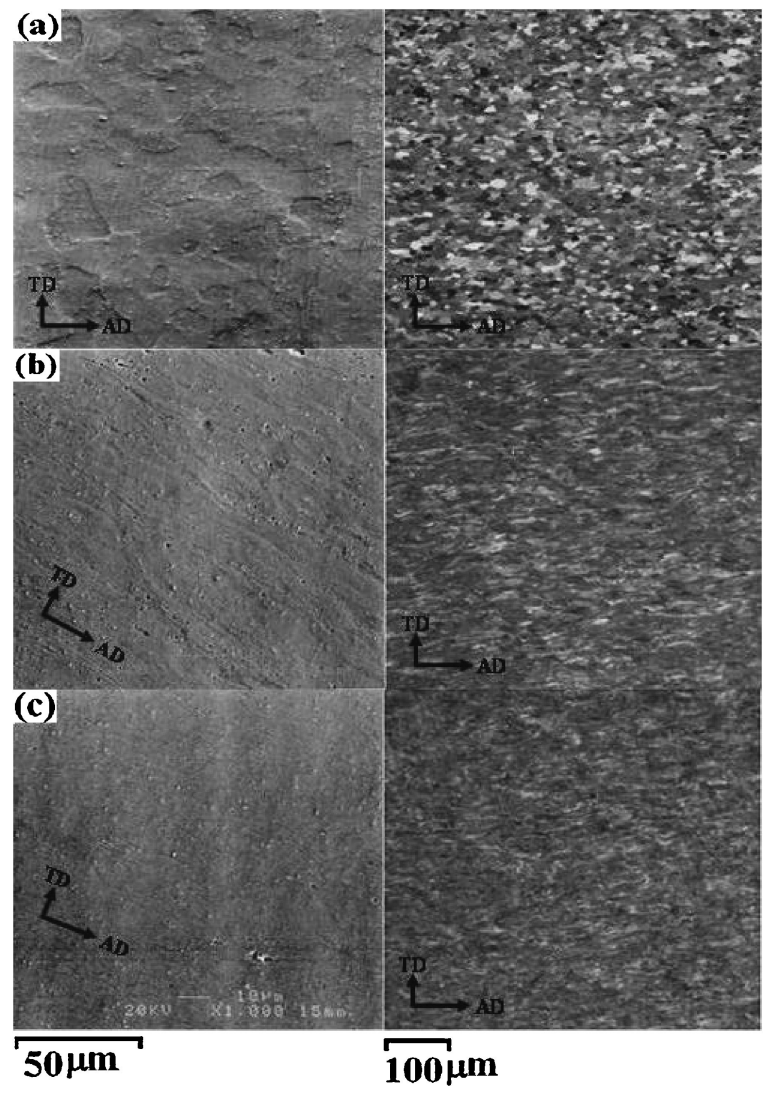

Fig. 3 Microstructure of longitudinal surface of zirconium alloy tubes observed by SEM (left) and polarized optical microscopy (right): (a) asreceived, (b) 1st pilgered and (c) 2nd pilgered tubes. AD and TD are longitudinal and tangential directions of tube, respectively.

Table 2 Micro-hardness changes of tube surfaces with pilgering.

\begin{tabular}{cccc}
\hline Specimen & $\begin{array}{c}\text { As-received } \\
\text { tube }\end{array}$ & $\begin{array}{c}\text { 1st pilgered } \\
\text { tube }\end{array}$ & $\begin{array}{c}\text { 2nd pilgered } \\
\text { tube }\end{array}$ \\
\hline $\begin{array}{c}\text { Hardness of } \\
\text { cross-sectional } \\
\text { surface } \\
\text { Hv }\end{array}$ & 172 & 218 & 246 \\
\hline $\begin{array}{c}\text { Hardness of } \\
\text { longitudinal } \\
\text { surface } \\
\text { Hv }\end{array}$ & 180 & 233 & 252 \\
\hline
\end{tabular}

size refinement and work hardening because the pilgering process is a kind of plastic deformation. Hardness change due to the grain size refinement is estimated by Hall-Petch relationship. ${ }^{11,12)}$ On the assumption of constant PearlsNabarro stress, the rate of the hardness changes in the crosssectional surface by 1 st and 2nd pilgering are 1.59 and 1.17, respectively, which are slightly higher than those of measured values of 1.26 and 1.13. The difference may be due to work hardening effect because dislocation density is increased by the number of pilgering and the Pearls-Nabarro stress depends on Burgers vector and dislocation length. Although it is difficult to precisely evaluate hardness change with the measurement direction, the improved hardness can be well described by grain size refinement and work hardening.

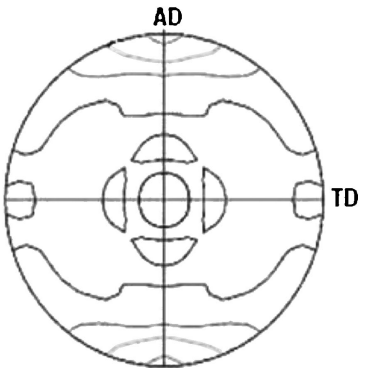

(10̄̄o)

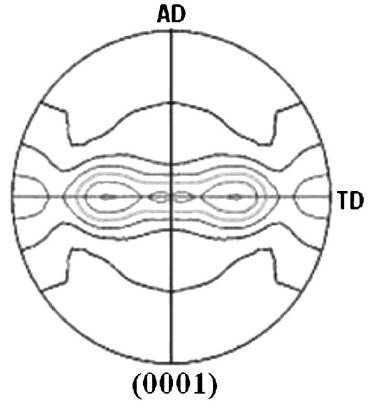

Fig. 4 (1010) and (0001) pole figures of as-received zirconium alloy tube, where $\mathrm{AD}$ and $\mathrm{TD}$ are longitudinal and tangential directions of tube, respectively. Contour levels: $0.5,1,1.5,2,2.5,3$.
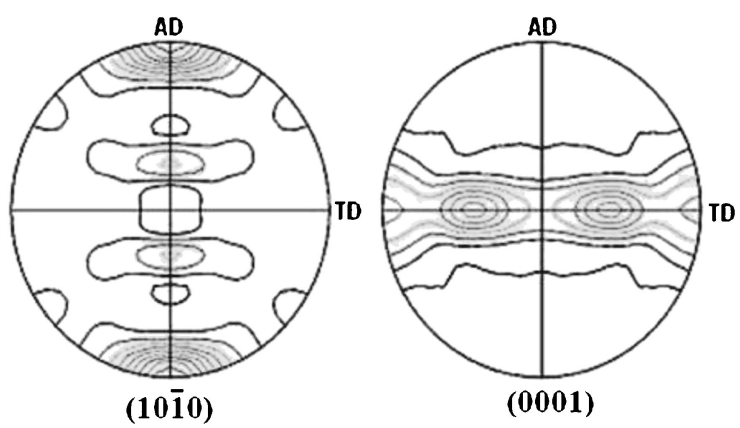

Fig. 5 (1010) and (0001) pole figures of 1st pilgered zirconium alloy tube, where $\mathrm{AD}$ and $\mathrm{TD}$ are longitudinal and tangential directions of tube, respectively. Contour levels: 0.5, 1, 1.5, 2, 2.5, 3, 3.5, 4, 4.5, 5, 5.5.
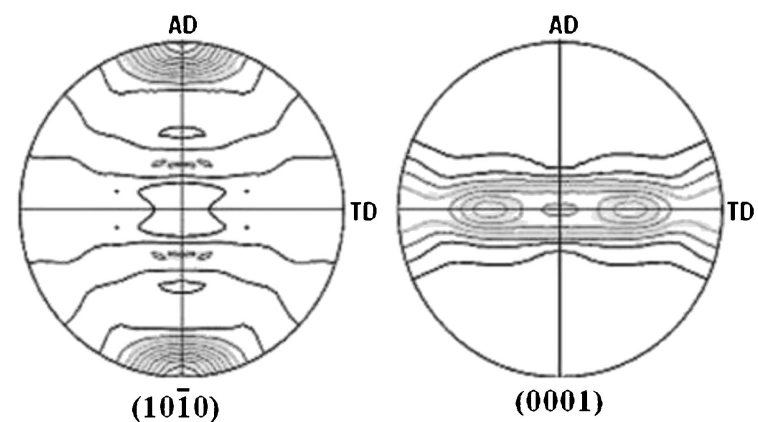

Fig. 6 (1010) and (0001) pole figures of 2nd pilgered zirconium alloy tube, where $\mathrm{AD}$ and $\mathrm{TD}$ are longitudinal and tangential directions of tube, respectively. Contour levels: $0.5,1,1.5,2,2.5,3,3.5,4,4.5,5,5.5,6$.

\subsection{Crystallographic texture}

X-ray diffraction technique was applied to study the pilgering effect on the crystallographic texture change. Figures 4, 5 and 6 are the (1010) and (0001) pole figures of the pilgered zirconium alloy tubes reconstructed from the orientation distribution function (ODF). ${ }^{9}$ As show in Fig. 4, the (0001) basal poles of the as-received specimen are split toward the tangential direction (TD) with symmetry, so called, TD split type. The $\{10 \overline{1} 0\}$ prismatic poles of the specimen are concentrated to the longitudinal direction (AD) with symmetry, so called, AD concentration type. It means that for the as-received specimen, the normal of basal planes expressed as the (0001) pole is mainly distributed in the angle of about 40 degrees from the sample normal direction (ND) 
toward TD, and lots of the $\{10 \overline{1} 0\}$ prismatic planes are distributed to the perpendicular to the longitudinal direction of the tube. Figure 5 is the reconstructed pole figures of $1 \mathrm{st}$ pilgered zirconium alloy tube. The basal and prismatic pole densities increase in the positions of TD split type and AD concentration type, respectively. Figure 6 is the reconstructed pole figures of 2 nd pilgered zirconium alloy tube. The 2nd pilgering tends to form the strong $\langle 10 \overline{10} 0\rangle / / \mathrm{AD}$ fiber texture with an orientation spread around $\mathrm{AD}$, though a peak of the (0001) poles remains in the position of about 40 degrees from ND toward TD. It means that 2 nd pilgering results in refined grains with more random orientation distribution around the longitudinal direction. Comparing Figs. 5 and 6 with Fig. 4, it is obtained that the normal of (0001) plane is mainly distributed in the angle of about 40 degrees from the sample normal toward TD and the $\langle 10 \overline{10}\rangle$ direction is significantly oriented along the longitudinal direction $(\mathrm{AD})$ of tube by pilgering.

It is interesting to understand why pilgering develops the above crystallographic texture. It is known that the texture formation by pilgering is significantly dependent upon Qratio. In this study, Q-ratios of the tubes after 1st and 2nd pilgering are 1.13 and 1.99 , respectively. In case of $\mathrm{Q}>1$, radial strain is greater than tangential strain during pilgering, which means that the largest and next compressive stresses exist to radial and tangential directions during pilgering, respectively. Since such stresses result in making a preferred orientation by slip deformation, the random oriented grains tend to align for the $c$-axis to be parallel to the radial direction by the stress condition during pilgering. Because the primary slip system of zirconium has been found to be the prismatic slip on $\{10 \overline{1} 0\}$ planes along $\langle 1 \overline{2} 10\rangle$ directions, slip of zirconium is dominant for the deformation parallel to the a-axis, whereas twin with rotation of unit cell is dominant for the deformation parallel to the $c$-axis, respectively. ${ }^{13)}$ Accordingly, the stress conditions during pilgering result in forming a crystallographic texture similar to that of a rolled sheet in which the $c$-axis inclines by about 40 degrees from ND toward TD and the $\langle 10 \overline{1} 0\rangle$ direction, being a stable orientation in tension, is parallel to the rolling direction.

Although the most common method to characterize crystallographic texture is the presentation of pole figures where stereographic projection specifies the orientation of the crystallographic planes in space, the pole figures are only qualitative representation of the texture. ${ }^{14)}$ In this study, the orientation distribution function (ODF) of the zirconium alloy tube was determined to quantitatively evaluate crystallographic texture change with pilgering. Figure 7 is the ODFs of the pilgered zirconium alloy tubes in the form of Euler plots at 5 degrees intervals of $\varphi_{2}$. The intensity peaks are referred to in the Euler plots, where the intensity of random orientation is unity. Orientation groups with the $c$-axis parallel to the longitudinal (AD), tangential (TD) and normal (ND) directions of the tube correspond to $\left(\varphi_{1}, \Phi\right)$ angles of $(90,90),(0,90)$ and $(0,0)$ degrees in each $\varphi_{2}$ section of Euler space, respectively. As shown in Fig. 7, the maximum orientation density of the zirconium alloy tube is 3.8 for as-received, 8.7 for 1st pilgered and 7.8 for 2 nd pilgered tubes, respectively. It supports that a preferred orientation is mainly formed by 1 st pilgering.
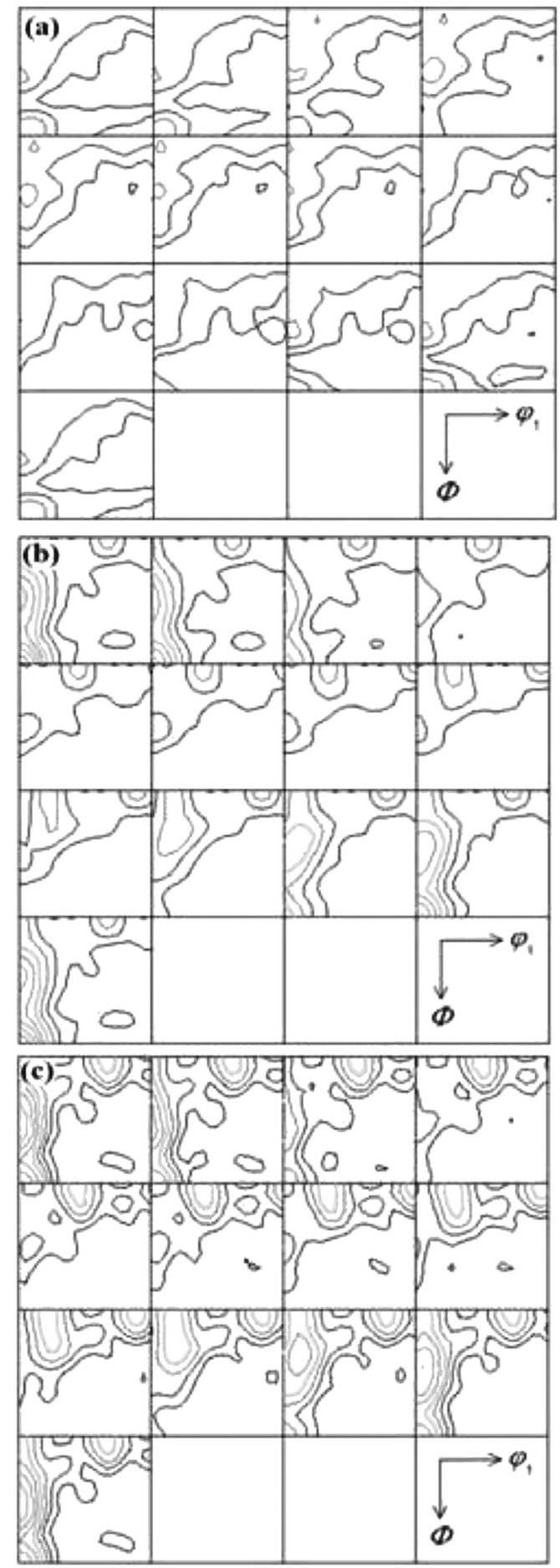

Fig. 7 ODFs of zirconium alloy tubes: (a) as-received (Max $=3.8$ ), (b) 1 st pilgered $(\operatorname{Max}=8.7)$ and $(c) 2$ nd pilgered $(\operatorname{Max}=7.8)$. Contour levels: $1,2,3,4,5,6,7,8$.

Comparing with a standard orientation chart of $\mathrm{HCP}$ structure, preferred orientations can be evaluated in more detail. ${ }^{15)}$ In the $\varphi_{2}$ section of 0 degree including the maximum peak, a preferred orientation with highest intensity changes from $(\overline{1} 2 \overline{1} 0)[10 \overline{1} 0]$ at the position $\left(\varphi_{1}, \Phi\right)=(0,90)$ for the as-received tube to $(\overline{1} 2 \overline{1} 4)[10 \overline{1} 0]$ at the position $\left(\varphi_{1}, \Phi\right)=$ $(0,40)$ for the 2 nd pilgered tube. This suggests that the progress of pilgering causes a gradual orientation change from $(\overline{1} 2 \overline{1} 0)[10 \overline{10}$ ] to $(\overline{1} 2 \overline{1} 4)[10 \overline{1} 0]$, which is the same as a preferred orientation in a rolled titanium sheet. ${ }^{16)}$ The 
Table 3 Changes in corrosion potential and corrosion rate of exposed tube surfaces with pilgering.

\begin{tabular}{|c|c|c|c|c|c|c|}
\hline \multirow{2}{*}{$\begin{array}{c}\text { Specimen } \\
\text { Surface }\end{array}$} & \multicolumn{2}{|c|}{ As-received tube } & \multicolumn{2}{|c|}{ 1st pilgered tube } & \multicolumn{2}{|c|}{ 2nd pilgered tube } \\
\hline & Longitudinal & Cross-sectional & Longitudinal & Cross-sectional & Longitudinal & Cross-sectional \\
\hline $\begin{array}{c}\text { Corrosion potential, } \\
E / \mathrm{V}_{\mathrm{SHE}}\end{array}$ & -0.552 & -0.416 & -0.562 & -0.651 & -0.579 & -0.767 \\
\hline $\begin{array}{l}\text { Corrosion rate, } \\
i / 10^{-7} \mathrm{Acm}^{-2}\end{array}$ & 3.56 & 1.88 & 10.44 & 11.01 & 11.88 & 12.02 \\
\hline
\end{tabular}
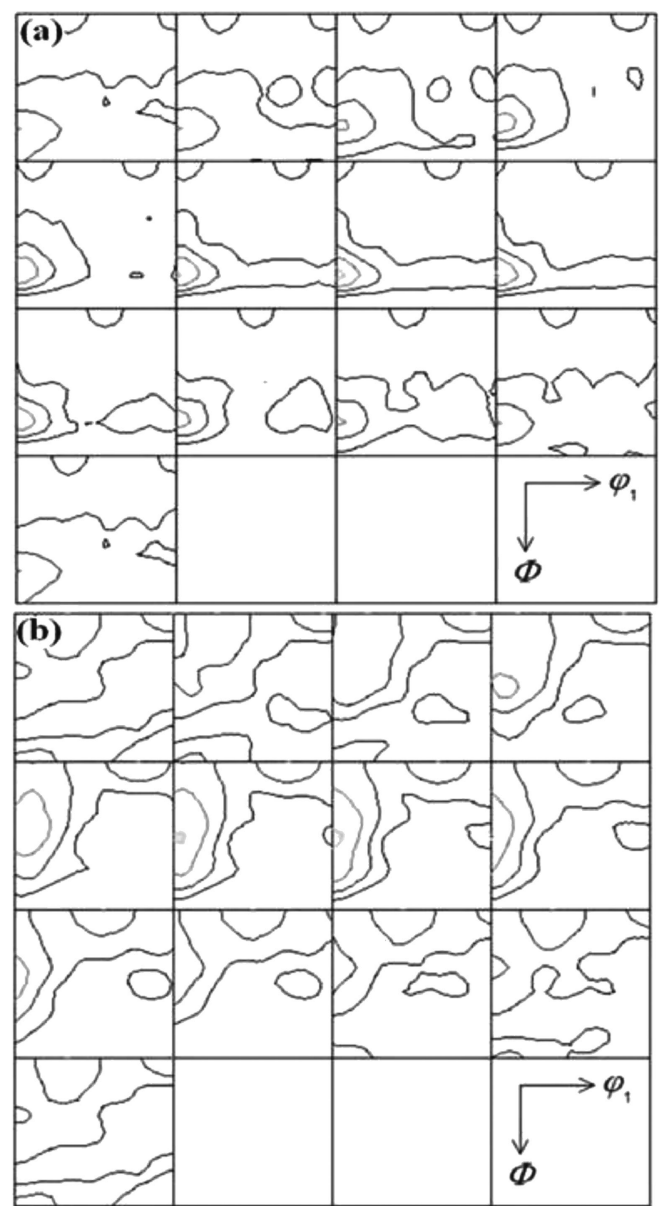

Fig. 8 ODFs of annealed zirconium alloy tubes: (a) as-received tube after annealing at $760^{\circ} \mathrm{C}$ for $2 \mathrm{~h}(\operatorname{Max}=4.2)$ and (b) 1 st pilgered tube after annealing at $650^{\circ} \mathrm{C}$ for $2 \mathrm{~h}(\mathrm{Max}=4.2)$. Contour levels: $1,2,3,4$.

as-received and 1st pilgered tubes prepared in this study were, however, annealed before the next pilgering at 760 and $650^{\circ} \mathrm{C}$, respectively. Accordingly, it is necessary to study the texture evolution by deformation and annealing. Figure 8 is the ODFs of the zirconium alloy tube after intermediate annealing for additional pilgering. As shown in Fig. 8, the maximum orientation densities of the tubes before each pilgering are the same value of about 4.2 but their preferred orientations are different, being $(02 \overline{2} 1)[2 \overline{1} \overline{1} 0]$ before 1 st pilgering and (01 12$)[2 \overline{1} \overline{1} 0]$ before 2 nd pilgering. These textures correspond to the texture change from (12 $\overline{1} 0)[10 \overline{1} 0]$ to $(\overline{1} 2 \overline{1} 4)[10 \overline{1} 0]$ by pilgering in terms of the tilt angle of the $c$-axis from ND toward TD, though the tilt angle of the $c$-axis toward TD decreased gradually and the 30 degrees rotation around the $c$-axis took place during annealing. Hence, it is speculated that the pilgering process

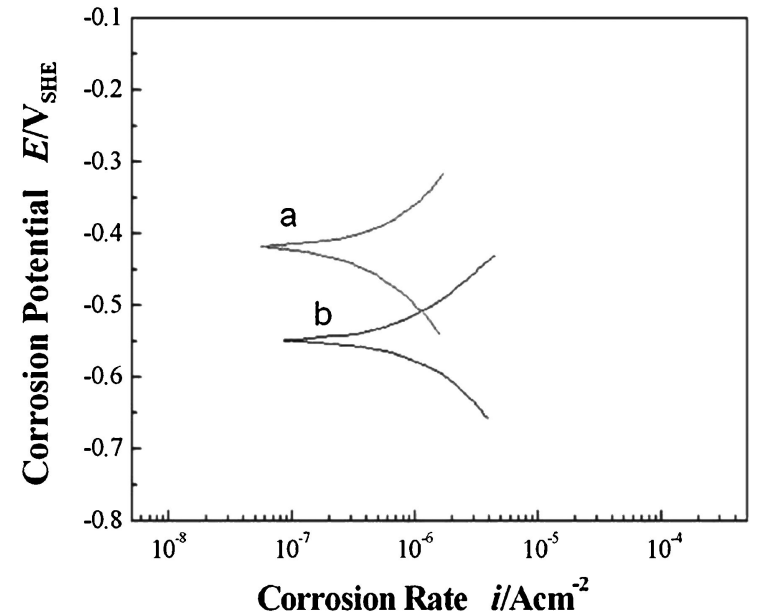

Fig. 9 Typical polarization curves of as-received zirconium alloy tube with exposed surface in dearated aqueous $5 \% \mathrm{NaCl}$ solution $(\mathrm{pH}=6.3)$ at $20^{\circ} \mathrm{C}$ : (a) cross-sectional and (b) longitudinal surfaces.

essentially induces a texture change to the (12 $\overline{1} 4)[10 \overline{1} 0]$ stable orientation.

\subsection{Anisotropic corrosion behavior}

Figure 9 is typical polarization curves on different surfaces of zirconium alloy tubes in dearated aqueous $5 \% \mathrm{NaCl}$ solution $(\mathrm{pH}=6.3)$ at $20^{\circ} \mathrm{C}$. As shown in Fig. 9, there is no passive region in the polarization curves. Table 3 is the corrosion potential and corrosion rate of exposed tube surfaces. As shown in Table 3, the corrosion potential and corrosion rate of the zirconium alloy tubes in dearated aqueous $5 \% \mathrm{NaCl}$ solution $(\mathrm{pH}=6.3)$ at $20^{\circ} \mathrm{C}$ are in the range of $-0.552 \sim-0.767 \mathrm{~V}_{\mathrm{SHE}}$ and $1.88 \times 10^{-7} \sim 12.02 \times$ $10^{-7} \mathrm{~A} / \mathrm{cm}^{2}$, respectively. Different values of corrosion potential and corrosion rate were observed on the crosssectional and longitudinal surfaces. Pilgered tubes show lower corrosion potential and higher corrosion rate than asreceived tube. Corrosion behavior is usually dependent upon metallurgical parameters such as grain size, crystallographic texture, precipitates and dislocation density. Considering fabrication process of zirconium alloy tube in this study, grain size refinement by pilgering should significantly influence reducing corrosion resistance of the zirconium alloy tubes because the pilgering as a plastic deformation process results in increasing grain boundary area. Besides the effect of grain size refinement, dislocation density can also influence the corrosion behavior because grain size refinement by pilgering simultaneously increases dislocation density, and a strained surface layer is more electrochemically active so that the corrosion potential decreases while the corrosion rate increases. ${ }^{17,18)}$ 
One of interesting observation is the anisotropic corrosion behavior of pilgered zirconium alloy tube in which different values of corrosion potential and corrosion rate were observed on the cross-sectional and longitudinal surfaces as shown in Fig. 9. Especially, in case of as-received tube which has equiaxed grains as shown in Figs. 2 and 3, the corrosion rate is greater on longitudinal surface than on crosssectional surface. Since grain boundary area, precipitates and dislocation density on longitudinal surface of the as-received tube are similar to those on cross-sectional surface, other metallurgical factors like crystallographic texture can be considered as one of effective parameters to influence the anisotropic corrosion behaviors. Generally, the surface with lower planar atomic density shows higher corrosion rate because corrosion is electrochemical reaction between surface atom and ion in aqueous solution which is related to surface atomic density. ${ }^{19,20)}$ The planes with high planar atomic densities of zirconium are (0001), (11 $\overline{2} 0)$ and (10 $\overline{1} 0)$ planes in which planar atomic densities are 1.15, 0.73 and 0.63 , respectively, and (1011) plane has also high planar atomic density $(\sim 1)$. These planes of the HCP structure have lower corrosion rate than other crystal planes with higher indices. Considering crystallographic texture analysis of the as-received tube, as shown in Fig. 4 and Fig. 7(a), \{10 $\overline{1} 0\}$ poles of the as-received tube which has equiaxed grains are concentrated to the longitudinal direction, i.e. $\{1010\}$ planes are parallel to cross-sectional surface, whereas (0001) poles are split from ND toward the tangential direction, i.e. various crystal planes with relatively high indices are parallel to longitudinal surface. Accordingly, the lack of crystal planes with high planar atomic density on longitudinal surface might result in the higher corrosion rate than on cross-sectional surface in as-received tube.

For the pilgered tubes, different anisotropic corrosion behavior was observed, in which cross-sectional surface of each pilgered tube showed slightly higher corrosion rate than their longitudinal surfaces. Corrosion rate of the tube increases abruptly after 1st pilgering, which slightly further increases after 2nd pilgering. Pilgering process significantly reduces the grain size, increases the dislocation density and changes the crystallographic texture of the zirconium alloy tube. All of them can influence the corrosion behavior of pilgered tubes. Although it is difficult to quantitatively distinguish the effect of each factor at this moment, the fact that higher corrosion rate is observed on cross-sectional surface with heavily reduced grain size and preferentially oriented $\{10 \overline{1} 0\}$ planes than on longitudinal surface with various crystal planes of relatively high indices including (12) 14 ) suggests that the grain size refinement and increased dislocation density by pilgering plays more important role than crystallographic texture on corrosion behavior. Likewise, the 2nd pilgering, in which the reduction of grain size somewhat occurs but the concentration of $\{10 \overline{1} 0\}$ poles to the longitudinal direction, i.e. the increase of $\{10 \overline{1} 0\}$ planes parallel to cross-sectional surface hardly occurs, more or less increases the corrosion rate on both surfaces from the $1 \mathrm{st}$ pilgered state. However, an increment of corrosion rate from the 1 st pilgered state by 2 nd pilgering is slightly larger on longitudinal surface than on cross-sectional surface. This may be due to the change in preferred orientation on longitudinal surface from $(\overline{1} 2 \overline{1} 0)$ plane to $(\overline{1} 2 \overline{1} 4)$ one, having lower planar atomic density, by 2 nd pilgering, because there is no significant change in preferred orientation on cross-sectional surface. From the above discussion, it is concluded that anisotropic corrosion behavior is related to crystallographic anisotropy.

\section{Conclusions}

(1) Zirconium alloy tube with equiaxed grain size of about $28 \mu \mathrm{m}$ became the tubes with average grain size of $11 \mu \mathrm{m}$ after 1st pilgering, and $8 \mu \mathrm{m}$ after $2 \mathrm{nd}$ pilgering, respectively. Aspect ratios of the elongated grains on longitudinal surface are 6 for 1 st pilgered and 12 for 2nd pilgered tubes, respectively.

(2) Micro-hardness of pilgered zirconium alloy tubes depends on the pilgering process and measurement direction. The micro-hardnesses of as-received, 1st and 2nd pilgered tubes are 172,218 and $246 \mathrm{Hv}$ for their cross sectional surfaces and 180, 233 and $252 \mathrm{Hv}$ for their longitudinal surfaces, respectively.

(3) X-ray diffraction analysis reveals that the (0001) basal poles of the as-received specimen are split toward the tangential direction (TD) with the angle of about 40 degrees from the sample normal direction (ND), and the $\{10 \overline{1} 0\}$ prismatic poles are concentrated to the longitudinal direction (AD). The 1st pilgering of the zirconium alloy tube results in increasing the basal and prismatic pole densities to TD split type and $\mathrm{AD}$ concentration type, respectively. Further pilgering produces the alloy tube that has the more developed TD split type texture. Orientation distribution function (ODF) of the zirconium alloy tube with pilgering shows that a preferred orientation is mainly formed by 1 st pilgering. Intermediate annealing before pilgering reduces preferred orientations of the zirconium alloy tubes. However, texture of the zirconium alloy tube is developed to (12 $\overline{1} 4)$ [10 $\overline{1} 0]$ with a significant spread around [10시 parallel to AD by further pilgering.

(4) The corrosion potential and corrosion rate of the zirconium alloy tubes in dearated aqueous $5 \% \mathrm{NaCl}$ solution $(\mathrm{pH}=6.3)$ at $20^{\circ} \mathrm{C}$ are in the range of $-0.552 \sim-0.767$ $\mathrm{V}_{\text {SHE }}$ and $1.88 \times 10^{-7} \sim 12.02 \times 10^{-7} \mathrm{~A} / \mathrm{cm}^{2}$, respectively. Pilgered tubes show lower corrosion potential and higher corrosion rate than as-received tube because of grain size refinement and increased dislocation density.

(5) Crystallographic anisotropy also influences corrosion behavior of the zirconium alloy tubes. As-received tube with equiaxed grains shows higher corrosion rate on longitudinal surface than on cross-sectional surface, because the former is composed of various crystal planes with relatively high indices but the latter consists mainly of the $\{10 \overline{1} 0\}$ planes. However, pilgered tubes show higher corrosion rates on cross-sectional surfaces than on longitudinal surfaces because the grain size refinement more predominantly influences corrosion behavior than crystallographic texture. On the other hand, the change in preferred orientation from ( $\overline{1} 2 \overline{1} 0)$ plane to $(\overline{1} 2 \overline{1} 4)$ one by further pilgering might lead to a slightly larger increment of corrosion rate on longitudinal surface than on cross-sectional surface having nearly the same amount of $\{10 \overline{1} 0\}$ planes. 


\section{Acknowledgement}

Neutron Beam Application Lab carried out this work which was supported by the Korea Science and Engineering Foundation (KOSEF) through the National Research Laboratory funded by the Ministry of Education, Science and Technology (Grant number M1060000024806J000024810).

\section{REFERENCES}

1) E. Tenckhoff: Zirconium in Nuclear Application, (American Society for Testing and Materials STP 551, Philadelphia, 1974) pp. 179-200.

2) K. L. Murty and I. Charit: Prog. Nuclear Energy 48 (2006) 325-359.

3) Y. Choi, J. W. Lee, Y. W. Lee and S. I. Hong: J. Nucl. Mater. 256 (1998) 124-130

4) S. W. Banovic, M. D. Vaudin, T. H. Gnaeupel-Herold, D. M. Saylor and K. P. Rodbell: Mater. Sci. Eng. A 380 (2004) 155-179.

5) Y. Choi and H. Inoue: Mater. Sci. Forum 558 (2007) 1379-1371.

6) Y. N. Wang and J. C. Huang: Mater. Chem. Phys. 81 (2003) 11-26.

7) Y. Choi, E. J. Shin and H. Inoue: Phys. B 385 (2006) 529-531.
8) K. Vaibhaw, S. V. R. Rao, S. K. Jha, N. Saibaab and R. N. Jayaraj: J. Nucl. Mater. 383 (2008) 71-77.

9) H. J. Bunge: Int. Mater. Rev. 32 (1987) 265-291.

10) H. Inoue and N. Inakazu: J. Japan Inst. Metals 58 (1994) 892-898.

11) E. O. Hall: Proc. Phys. Soc. 64 (1951) 747-753.

12) N. J. Petch: J. Iron Steel Inst. 174 (1953) 25-28.

13) E. Tenckhoff: Deformation Mechanisms, Texture, and Anisotropy in Zirconium and Zircaloy, (American Society for Testing and Materials STP 966, Philadelphia, 1988) pp. 45-54.

14) H. R. Wenk and U. F. Kocks: Metall. Trans. A 18A (1987) 10831092.

15) N. Inakazu and H. Inoue: J. Japan Inst. Metals 52 (1988) 18-25.

16) H. Inoue and N. Inakazu: Proc. 8th Int. Conf. on Texture of Materials (ICOTOM 8), ed. by J. S. Kallend and G. Gottstein, (The Metallurgical Society, 1988) pp. 997-1004.

17) K. V. M. Krishna, S. K. Sahoo, I. Samajdar, S. Neogy, R. Tewari, D. Srivastava, G. K. Dey, G. H. Das, N. Saibaba and S. Banarjee: J. Nucl. Mater. 383 (2008) 78-85.

18) W. Li and D. Y. Li: Appl. Surf. Sci. 240 (2005) 388-395.

19) C. R. McCall, M. A. Hill and R. S. Lillard: Corros. Eng. Sci. Technol. 40 (2005) 337-343.

20) R. S. Lillard: Electrochem. Solid-State Lett. 6 (2003) 29-31. 